EXTENDED REPORT

\title{
Endophthalmitis associated with the Ahmed glaucoma valve implant
}

\author{
A A Al-Torbak, S Al-Shahwan, I Al-Jadaan, A Al-Hommadi, D P Edward
}

Br J Ophthalmol 2005;89:454-458. doi: 10.1136/bjo.2004.049015

See end of article for authors' affiliations

......................

Correspondence to: Abdullah A Al-Torbak, $M D$, FRCS, King Khaled Eye Specialist Hospital, PO Box 7191 Riyadh 11462, Saudi Arabia; atorbaq@ health.net.sa

Accepted for publication 1 September 2004

\begin{abstract}
Aim: To investigate the rate, risk factors, clinical course, and treatment outcomes of endophthalmitis following glaucoma drainage implant (GDI) surgery.

Methods: A computerised relational database search was conducted to identify all patients who were implanted with Ahmed glaucoma valve (AGV) and developed endophthalmitis following surgery at the King Khaled Eye Specialist Hospital in Riyadh, Saudi Arabia, between 1 January 1994 and 30 November 2003. Only medical records of the patients who developed endophthalmitis were retrospectively reviewed. Results: 542 eyes of 505 patients who were on active follow up were included in the study. Endophthalmitis developed in nine (1.7\%) eyes; the rate was five times higher in children than in adults. Delayed endophthalmitis (developed 6 weeks after surgery) occurred in eight of nine eyes. Conjunctival erosion overlying the AGV tube was present in six of nine eyes. Common organisms isolated in the vitreous included Haemophilus influenzae and Streptococcus species. Multiple regression analysis revealed that younger age and conjunctival erosion over the tube were significant risk factors associated with endophthalmitis.

Conclusion: Endophthalmitis is a rare complication of GDI surgery that appears to be more common in children. Conjunctival dehiscence over the GDI tube seems to represent a major risk factor for endophthalmitis. Prompt surgical revision of an exposed GDI tube is highly recommended.
\end{abstract}

G laucoma drainage implants (GDIs) have become an important method of controlling intraocular pressure (IOP) in patients with refractory glaucoma. Surgery with GDIs is associated with similar operative and postoperative complications that may occur after filtering surgery such as hypotomy, hyphaema, cataract, corneal decompensation, and failure to control IOP. ${ }^{1}$ In addition, several unique complications may develop with GDIs related to the presence of an implanted foreign body such as diplopia ${ }^{2}$ and transcorneal tube erosion. ${ }^{3}$

Although endophthalmitis is a rare complication after GDI surgery, the exact rate is not known. ${ }^{4}$ Several retrospective studies of GDIs have included a single case or a few cases of endophthalmitis resulting in rates ranging from $0.8 \%$ to $6.3 \% .^{5-19}$

We report the rate, clinical course, risk factors, and treatment outcomes of endophthalmitis associated with Ahmed glaucoma valve implant (New World Medical, Rancho Cucamonga, CA, USA) at one institution.

\section{METHODS}

This study was reviewed and approved by the institutional review board of the King Khaled Eye Specialist Hospital (KKESH). A computerised relational database search was conducted to identify all patients who were implanted with Ahmed glaucoma valve (AGV), surgery at the King Khaled Eye Specialist Hospital in Riyadh, Saudi Arabia, between 1 January 1994 and 30 November 2003. This group of patients was further screened to identify those who were on active follow up and had no concurrent procedures performed with the AGV implant. Patients who developed AGV related endophthalmitis in this group were included in this study. Only medical records of the patients who developed endophthalmitis were retrospectively reviewed. Patients identified were divided into adult and paediatric groups; those below 18 years of age were considered children as defined by the World Health Organization.
Multiple surgeons performed the AGV implant procedures. In the majority of cases a limbal based conjunctival flap was created between superior and lateral recti muscles. The valve plate was secured $8-10 \mathrm{~mm}$ posterior to the limbus using an 8-0 non-absorbable suture. The tube was cut to an appropriate length and inserted into the anterior chamber through a 23 gauge needle track and covered by either donor sclera, dura, or pericardial patch graft. Autologous scleral patch graft was not used in any of the procedures. Patients younger than 6 months with an axial length less than $22 \mathrm{~mm}$ received the paediatric model (AGV; model S1). Otherwise the adult model (AGV; model S2) was used. The AGV was the only glaucoma valve implant used at KKESH during the period of the study and other glaucoma drainage implants were not available for comparison.

Based on the chart review, data of patients who developed endophthalmitis following AGV implant surgery were collected and reviewed. This included demographic information, clinical settings, pertinent operative and preoperative data, culture sites, and type of organisms. In addition, treatments and treatment outcomes were also noted. Diagnosis of endophthalmitis was based on clinical findings and ultrasonography.

A multiple regression analysis was performed to determine how the variables of age (above and below 18 years of age) and the presence or absence of conjunctival erosion related to endophthalmitis. Statistical analyses were conducted using GB STAT 10.0 (Dynamic Microsystems, Inc, Silver Spring, MD, USA).

\section{RESULTS}

The relational database search identified 102 patients (113 eyes) under age 18 years (paediatric), and 403 patients (429 eyes) over age 18 years (adult) who underwent AGV surgery

Abbreviations: AGV, Ahmed glaucoma valve; GDI, glaucoma drainage implant; IOP, intraocular pressure 


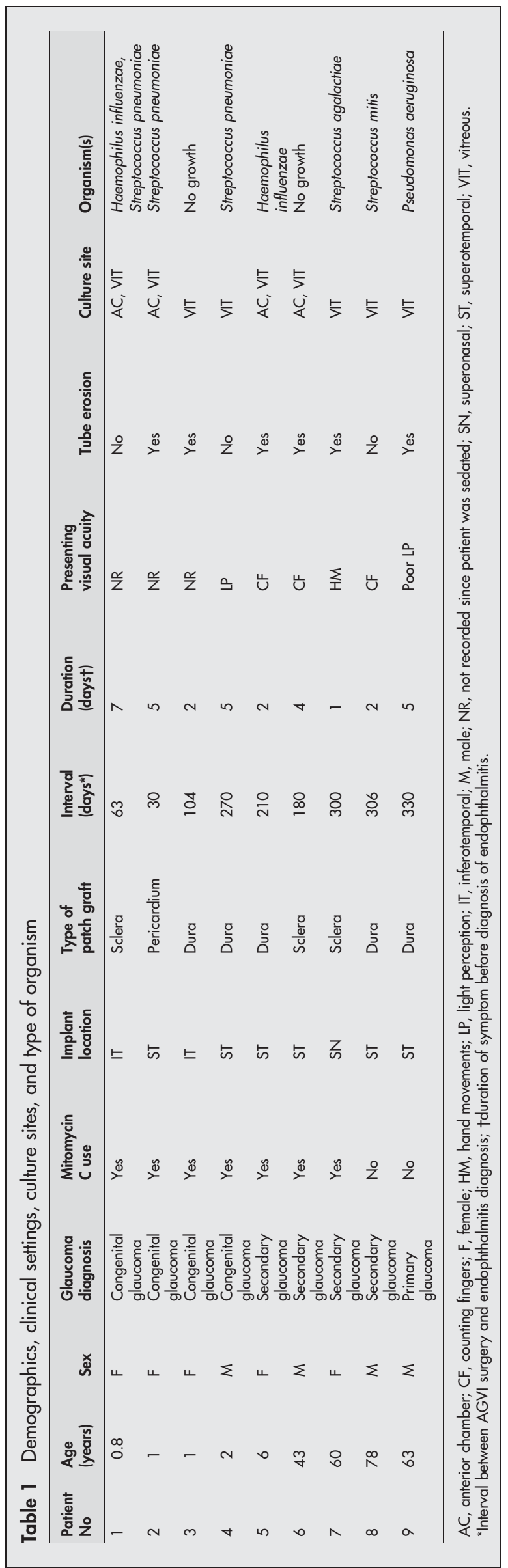

and were on active follow up. Endophthalmitis was detected in nine $(1.7 \%)$ of these eyes (table 1$)$; five $(4.4 \%)$ in the paediatric age group and four $(0.9 \%)$ in the adult age group. The mean age of all patients at the time of endophthalmitis was 28.3 years (range $0.8-78$ years); 2.2 years (range $0.8-$ 6 years) and 61 years (range $43-78$ years) in the paediatric and adult age groups, respectively. Types of glaucoma identified were congenital in four of nine eyes, secondary in four of nine eyes, and primary open angle in one of nine eye. The mean number of previous glaucoma surgeries was 1.1 (range 0-2). One eye had no previous glaucoma surgery, six eyes had one procedure, and two eyes had two procedures. The most common previous glaucoma surgery was trabeculectomy with antimetabolite (mitomycin C was used as an adjunct in eight of nine eyes). Three eyes received the paediatric model and six eyes received the adult model of the AGV respectively. No patient had more than one implant in these nine eyes. No glaucoma surgery had been performed after the initial implant surgery. Seven of the nine eyes had received mitomycin $\mathrm{C}$ during implant surgery. Owing to the dense corneal opacities and/or advanced glaucoma, none of the patients achieved a pre-infection visual acuity of better than 20/100. One child had history of conjunctivitis 10 days before development of endophthalmitis.

The median interval between AGV implant surgery and diagnosis of endophthalmitis was 206 days (range 63330 days). Delayed onset endophthalmitis (developed 6 weeks after surgery) occurred in eight of nine eyes, and the infection developed in one of nine eye within the first few weeks of surgery.

The median duration between onset of symptoms and presentation for diagnosis and treatment at KKESH was 3.7 days (range 1-7 days). All patients were treated for endophthalmitis on the day of presentation (table 2). Conjunctival erosion over the tube was noticed in six of nine eyes and four of six eyes had a Siedel positive leak. The site of the conjunctival erosion was near the limbus in three of six eyes, and in two of six eyes the conjunctival erosion was away from the limbus where the erosion extended through the patch graft to expose the tube. In one of six eyes, the site of the conjunctival erosion was at the tube plate junction. Purulent discharge was observed in the area of the erosion in two eyes.

Vitreous cultures were positive for the infecting organism(s) in seven of nine eyes and negative in two of nine eyes. Hemophilus influenzae and Streptococcus pneumoniae were isolated from the culture sites in children. In adults, organisms causing AGV related endophthalmitis included Streptococcus species and Pseudomonas aeruginosa.

In this series, one of nine eye was initially treated with evisceration because of severe infection with pain and no visual potential. Three of nine eyes underwent pars plana vitrectomy plus intravitreal antibiotics injection. In the remaining five of nine eyes, intravitreal antibiotics alone were administered during the vitreous tap. Intravitreal dexamethasone was administered in two eyes. The intraocular antibiotic regimen used in this series consisted of vancomycin and either an aminoglycoside or ceftazidime. Pars plana vitrectomy with intravitreal antibiotics injection did not appear to have an impact on the final visual acuity.

Multiple regression analyses revealed younger age $(<18$ years of age; $\mathrm{p}<0.05)$ and conjunctival erosion over tube $(\mathrm{p}<0.01)$ were significantly associated with the occurrence of endophthalmitis. The glaucoma drainage implant was removed at the time of intravitreal injection in four of nine eyes and left intact in five of nine eyes. Removal or retention of the AGV did not appear to influence the final visual acuity. 
Table 2 Treatment performed and clinical outcomes

\begin{tabular}{|c|c|c|c|c|c|c|c|c|c|c|c|}
\hline \multirow[b]{2}{*}{$\begin{array}{l}\text { Patient } \\
\text { No }\end{array}$} & \multirow{2}{*}{$\begin{array}{l}\text { Tap/injection } v \text { pars } \\
\text { plana vitrectomy/ } \\
\text { injection }\end{array}$} & \multirow{2}{*}{$\begin{array}{l}\text { Intravitreal } \\
\text { injections }\end{array}$} & \multirow[b]{2}{*}{$\begin{array}{l}\text { Implant } \\
\text { removed }\end{array}$} & \multirow[b]{2}{*}{$\begin{array}{l}\text { Sensitivity of } \\
\text { organism }\end{array}$} & \multicolumn{3}{|c|}{ Pre-infection } & \multirow[b]{2}{*}{$\begin{array}{l}\text { Follow up } \\
\text { (months) }\end{array}$} & \multicolumn{3}{|c|}{ Post-infection } \\
\hline & & & & & $\begin{array}{l}\text { Visual } \\
\text { acuity }\end{array}$ & $\begin{array}{l}\text { IOP } \\
\text { (mm Hg) }\end{array}$ & Medications & & $\begin{array}{l}\text { Visual } \\
\text { acuity }\end{array}$ & $\begin{array}{l}\text { IOP } \\
\text { (mm Hg) }\end{array}$ & Medication \\
\hline 1 & PPV & $\mathrm{V}, \mathrm{A}$ & No & V & $\mathrm{HM}$ & 14 & 2 & 4 & NLP & 0 & 0 \\
\hline 2 & Tap & $\mathrm{V}, \mathrm{C}$ & Yes & $V, B$ & $\mathrm{FL}$ & 18 & 0 & 9 & NLP & 5 & 0 \\
\hline 3 & Tap & $\mathrm{V}, \mathrm{A}$ & Yes & - & FO & 15 & 1 & 26 & CF & 11 & 3 \\
\hline 4 & Tap & $\mathrm{V}, \mathrm{A}$ & No & $\overline{\mathrm{V}}, \mathrm{E}$ & $\mathrm{FO}$ & 21 & 1 & 18 & $\mathrm{HM}$ & 9 & 2 \\
\hline 5 & PPV & $\mathrm{V}, \mathrm{C}, \mathrm{D}$ & No & $C, C E$ & $20 / 100$ & 20 & 1 & 14 & LP & 16 & 1 \\
\hline 6 & Tap & $\mathrm{V}, \mathrm{A}$ & No & - & $20 / 125$ & 20 & 1 & 17 & $20 / 200$ & 18 & 2 \\
\hline 7 & Tap & $\mathrm{V}, \mathrm{A}, \mathrm{D}$ & Yes & $\overline{\mathrm{V}}, \mathrm{P}$ & CF & 10 & 2 & 13 & $\mathrm{HM}$ & 15 & 2 \\
\hline 8 & PPV & $\mathrm{V}, \mathrm{C}, \mathrm{D}$ & No & $V, B$ & $20 / 100$ & 09 & 2 & 19 & $20 / 200$ & 14 & 2 \\
\hline 9 & Primary evisceration & NA & Yes & $T^{\prime}$ & $\mathrm{CF}$ & 20 & 2 & 6 & NLP & 0 & 0 \\
\hline
\end{tabular}

Three of nine patients had a final visual acuity outcome of no light perception and six of nine patients attained a final visual acuity of light perception or better. None achieved a final visual acuity of better than 20/200.

\section{DISCUSSION}

Glaucoma drainage implants (GDIs) have become increasingly useful in surgical management of glaucoma that is refractory to standard filtering surgery. Although intraocular pressure may be successfully controlled, postoperative complications do occur. This large series from a single institution highlights the clinical features, risk factors, and outcomes that have been previously only presented in small case series.

In our series the overall rate of endophthalmitis was $1.7 \%$. We compared this rate with an analysis of endophthalmitis rates following all shunts in the literature. It appeared that the endophthalmitis rate in this series was fairly consistent with that reported in the literature (mean $2.0 \%$; range $0.8 \%-$ $6.3 \% ;^{5-19} 20$ see table 3 ). This suggests that the type of shunt device implanted does not influence the risk of endophthalmitis. However, the rate of endophthalmitis following AGV implant surgery in the paediatric age group was five times higher than adults in our study $(4.4 \% \quad v \quad 0.9 \%)$. Multiple regression analysis confirmed that younger age $(<18$ years $)$ was a significant risk factor for endophthalmitis. Interestingly, the rate of endophthalmitis in children appeared to parallel the rate of tube exposure in paediatric shunts (10-13\%), ${ }^{17}{ }^{21}$ which was five times higher than the rate reported for glaucoma implants in adults (0-2\%). ${ }^{92}$

Our series suggest that most cases (eight of nine) of endophthalmitis secondary to AGV implant surgery were delayed in onset ( 6 weeks after surgery). This concurs with isolated cases in series or individual case reports which also suggested most endophthalmitis following GDIs were delayed in onset. ${ }^{43-25}$ However, isolated cases of early endophthalmitis associated with GDIs have also been reported. Perkins ${ }^{26}$ reported early postoperative endophthalmitis following placement of a Molteno implant in an adult patient. In our series the patient with early endophthalmitis was a child. Moreover, endophthalmitis has also been described after tube repositioning ${ }^{27}$ and needling. ${ }^{28}$ Such presentations were not seen in our series.

Tube exposure following conjunctival erosion in AGV implant appeared be a major risk factor for the development of endophthalmitis as shown by regression analysis in our series. Other series have also reported conjunctival tube erosion without risk analysis. Gedde $e t a l^{4}$ reported four cases of endophthalmitis associated with GDIs. In their series all cases were associated with conjunctival erosion overlying the tube. Recently, Morad et al ${ }^{17}$ reported three cases of endophthalmitis following AGV. Two of these cases were noted to have tube exposure at the time of presentation. In our series, six of nine eyes were found to have conjunctival erosion over the tube at the time of presentation. The conjunctival erosion was at the limbus in three of six eyes,

Table 3 Endophthalmitis associated with GDls reported in various studies

\begin{tabular}{|c|c|c|c|c|c|}
\hline Source & Study date & Number of cases & $\begin{array}{l}\text { Number of } \\
\text { endophthalmitis cases }\end{array}$ & $\%$ of endophthalmitis & Type of implant \\
\hline Munoz et $a l^{5}$ & 1991 & 53 & 1 & 1.9 & Molteno \\
\hline Hill et $a l^{6}$ & 1991 & 70 & 1 & 1.4 & Molteno \\
\hline Chihara et al ${ }^{7}$ & 1992 & 16 & 1 & 6.3 & White pump \\
\hline $\begin{array}{l}\text { The Krupin Eye Valve Filtering } \\
\text { Surgery Study Group }\end{array}$ & 1994 & 50 & 1 & 2 & $\begin{array}{l}\text { Krupin valve with } \\
\text { disc }\end{array}$ \\
\hline Lloyd et $a l^{9}$ & 1994 & 73 & 1 & 1.4 & Baerveldt \\
\hline Perkins et $a l^{10}$ & 1995 & 21 & 1 & 4.8 & Molteno \\
\hline Price and Wellemeyer ${ }^{11}$ & 1995 & 76 & 1 & 1.3 & Molteno \\
\hline Law et $a l^{12}$ & 1996 & 38 & 1 & 2.6 & Molteno \\
\hline Nguyen et $a l^{13}$ & 1998 & 107 & 1 & 0.9 & Baerveldt \\
\hline Diodeyre et $a l^{14}$ & 2001 & 35 & 1 & 2.6 & Ahmed \\
\hline Krishna ef al ${ }^{15}$ & 2001 & 65 & 2 & 3.1 & Baerveldt \\
\hline Taglia et $a l^{16}$ & 2002 & 27 & 1 & 3.7 & Molteno \\
\hline Morad et $a 1^{17}$ & 2003 & 60 & 3 & 5 & Ahmed \\
\hline Seah et $\left.a\right|^{18}$ & 2003 & 124 & 1 & 0.8 & Baerveldt \\
\hline Tsai et al ${ }^{19}$ & 2003 & 70 & 1 & 1.4 & Baerveldt \\
\hline Present study & 2004 & 542 & 9 & 1.7 & Ahmed \\
\hline Total & & 1427 & 27 & 1.9 & \\
\hline
\end{tabular}


and at other locations in others. It did not appear to be related to the conjunctival incision line which was a few millimetres away from the limbus in the majority of the cases. Reasons for conjunctival erosion over patch grafts and tube are not totally clear and are possibly multifactoral. Most patients had multiple previous conjunctival surgeries with exposure to antimetabolites; in addition seven of nine eyes had received mitomycin $C$ during implant surgery and this may have played a part in the erosion of the conjunctiva. The rate of tube erosion through the conjunctiva can be reduced by covering the anterior portion of the tube by a patch graft. Different tissues have been utilised as a patch graft and these include sclera, ${ }^{29}$ dura mater, ${ }^{30}$ fascia lata, ${ }^{31}$ pericardium, ${ }^{32}$ and autologous sclera. ${ }^{33}$ Conjunctival erosion overlying the tube in our series occurred despite the use of a dura mater patch graft in five eyes, a donor sclera patch graft in three eyes, and a pericardial patch graft in one eye. The eroded conjunctiva surrounding the tube probably serves as a conduit by which normal flora may pass from the ocular surface into the eye. Given the increased risk of endophthalmitis, we recommend prompt surgical revision in all cases in which there is an exposed tube of a GDI.

Organisms causing endophthalmitis following GDIs in children are Haemophilus influenzae, Streptococcus pneumonia or both. In our series, cultures revealed Streptococcus pneumonia in two eyes and $H$ influenzae in one eye. Both organisms were cultured from one eye (patient 4). Gedde et al, ${ }^{4}$ and Al-Torbaq and Edward ${ }^{24}$ reported $H$ influenzae caused endophthalmitis following GDIs in two separate paediatric patients. This is not surprising as $H$ influenzae and Streptococcus pneumonia are part of the normal bacterial flora of the conjunctiva and upper respiratory tract, and a common cause of infection in both tissues. ${ }^{34}$ In adults, organisms causing GDI related endophthalmitis include coagulase negative and coagulase positive Staphylococcus species, Streptococcus pneumonia, and Pseudomonas aeruginosa. ${ }^{4}{ }^{12} 26$ In our series other Gram positive organisms including Streptococcus agalactiae and Streptococcus mitis were isolated from the vitreous sample in two separate eyes. Pseudomonas aeruginosa was a cause of severe endophthalmitis in one eye that was initially treated by evisceration. It appears that in general, bacterial flora causing GDI related endophthalmitis in Saudi Arabia are similar to those reported in patients from the Western hemisphere.

Recommendations for the removal of the glaucoma shunt device at the time of treatment in an eye with endophthalmitis remain unclear. Gedde and Perkins recommended shunt removal at the time of treatment because of concerns the shunt might serve as a reservoir for the infectious organism. ${ }^{46}$ In contrast, others have reported successful outcomes with intravitreal antibiotics without removing the shunt device. ${ }^{236}$ In our series, there appeared to be no difference in final visual acuity relating to whether the implant was or was not removed at the time of treatment. However, it must be noted our sample size is too small to make any definite recommendations.

It is unclear whether pars plana vitrectomy with intravitreal antibiotics injection or vitreous tap with intravitreal antibiotics injection alone is the treatment of choice for GDI related endophthalmitis. Morad et al ${ }^{17}$ reported three cases of endophthalmitis following AGV implant surgery. All cases were treated with implant removal, vitrectomy and intravitreal antibiotics; two eyes progressed to phthisis. Francis et al ${ }^{25}$ reported poor outcome with vitreous tap and intravitreal antibiotics injection in a patient who developed endophthalmitis following a Baerveldt drainage implant despite rapid treatment. In our series it appeared that either initial approach to treatment (pars plana vitrectomy with intravitreal antibiotics or intravitreal antibiotic injection alone) did not have a significant impact on the final visual outcome. These findings may have been influenced by the relatively long interval between onset of symptoms and presentation.

In our series the visual outcome is poor. Of note is that most patients had poor visual acuity before the onset of infection because of either advanced glaucoma or corneal opacities.

In conclusion, endophthalmitis is a rare complication following AGV implant surgery and is usually delayed in onset. The rate of endophthalmitis following AGV implant surgery in the paediatric age group was five times higher than in adults. Conjunctival erosions over the AGV tube were present in most cases and seem to represent a major risk factor for endophthalmitis. Prompt surgical revision of such erosions is highly recommended.

\section{Authors' affiliations}

A A Al-Torbak, S Al-Shahwan, I Al-Jadaan, Department of Ophthalmology, King Khaled Eye Specialist Hospital, Riyadh, Saudi Arabia

A Al-Hommadi, Department of Research, King Khaled Eye Specialist Hospital, Riyadh, Saudi Arabia

D P Edward, Department of Ophthalmology, University of Illinois, Chicago, IL, USA

Presented in part as a paper at the annual meeting of the Saudi Ophthalmological Society, 2-5 March 2003, Riyadh, Saudi Arabia.

\section{REFERENCES}

1 Wilson MR, Mendis U, Paliwal A, et al. Long-term follow-up of primary glaucoma surgery with Ahmed glaucoma valve implant versus trabeculectomy. Am J Ophthalmol 2003; 136:464-70.

2 Coats DK, Paysse EA, Nania SO. Acquired pseudo-Brown's syndrome immediately following Ahmed valve glaucoma implant. Ophthalmic Surg Lasers 1999;30:396-7.

3 Al-Torbak A, Edward DP. Transcorneal tube erosion of an Ahmed valve implant in a child. Arch Ophthalmol 2001;119:1558-9

4 Gedde SJ, Scott IU, Tabandeh H, et al. Late endophthalmitis associated with glaucoma drainage implants. Ophthalmology $2001 ; 108: 1323-7$.

5 Munoz M, Tomey KF, Traverso C, et al. Clinical experience with the Molteno implant in advanced infantile glaucoma. J Pediatr Ophthalmol Strabismus 1991;28:68-72.

6 Hill R, Heuer DK, Baerveldt G, et al. Molteno implantation for glaucoma in young patients. Ophthalmology 1991;98:1042-6.

7 Chihara E, Kubota H, Takanashi T, et al. Outcome of white pump shunt surgery for neovascular glaucoma in Asians. Ophthalmic Surg 1992;23:666-71.

8 The Krupin Eye Valve Filtering Study Group. Krupin eye valve with disc for filtration surgery. Ophthalmology 1994;101:651-8.

9 Lloyd MA, Baerveldt G, Fellenbaum PS, et al. Intermediate results of a randomized clinical trial of the 350 versus $500 \mathrm{~mm}$ Baerveldt implant. Ophthalmology 1994;101:1456-1463.

10 Perkins TW, Cardaki UF, Eisele JR, et al. Adjunctive mitomycin C in Molteno implant surgery. Ophthalmology 1995;102:91-7.

11 Price FW Jr, Wellemeyer M. Long-term results of Molteno implants. Ophthalmic Surg 1995;26:130-5.

12 Law SK, Kalenak JW, Connor TB, et al. Retinal complications after aqueous shunt surgical procedures for glaucoma. Arch Ophthalmol 1996;114:1473-80.

13 Nguyen QH, Budenz DL, Parrish RK II. Complications of Baerveldt glaucoma drainage implants. Arch Ophthalmol 1998;116:571-5.

14 Djodeyre MR, Calvo JP, Gomez JA. Clinical evaluation and risk factors of time to failure of Ahmed glaucoma valve implant in pediatric patients. Ophthalmology 2001;108:614-620.

15 Krishna R, Godfrey DG, Budenz DL, et al. Intermediate-term outcomes of 350$\mathrm{mm}[2]$ Baerveldt glaucoma implants. Ophthalmology 2001;108:621-6.

16 Taglia DP, Perkins TW, Gangnon R, et al. J Glaucoma 2002;1 1:347-53.

17 Morad Y, Donaldson CE, Kim YM, et al. The Ahmed drainage implant in the treatment of pediatric glaucoma. Am J Ophthalmol 2003;135:821-9.

18 Seah SKL, Gazzard G, Aung T. Intermediate-term outcome of Baerveldt glaucoma implants in Asian eyes. Ophthalmology 2003;1 10:888-94.

19 Tsai JC, Johnson CC, Dietrich MS. The Ahmed shunt versus the Baerveldt shunt for refractory glaucoma. Ophthalmology 2003;110:1814-1821.

20 Topouzis F, Yu F, Coleman AL. Factors associated with elevated rates of adverse outcomes after cyclodestructive procedures versus drainage device procedures. Ophthalmology 1998;105:2276-2281.

21 Englert JA, Freedman SF, Cox TA. The Ahmed valve in refractory pediatric glaucoma. Am J Ophthalmol 1999;127:34-42.

22 Melamed S, Cahane M, Gutman L, et al. Postoperative complications after Molteno implant surgery. Am J Ophthamol 1991;1:319-22.

23 Krebs DB, Liebmann JM, Ritch R, et al. Late infectious endophthalmitis from exposed glaucoma setons [case report]. Arch Ophthalmol 1992;1 10:174-5. 
24 Al-Torbag A Edward DP. Delayed endophthalmitis in a child following an Ahmed Glaucoma Valve Implant. JAAPOS 2002;6:123-125.

25 Francis BA, Diloreto DA, Chong LP, et al. Late onset bacterial endophthalmitis following glaucoma drainage implantation. Ophthalmol Surg Lasers Imaging 2003;34:128-30.

26 Perkins TW. Endophthalmitis after placement of a Molteno implant. Ophthalmic Surg 1990;21:733-4.

27 Fanous MM, Cohn RA. Propionibacterium endophthalmitis following Molteno tube repositioning. J Glaucoma 1997;6:201-2.

28 Chen PP, Palmberg PF. Needling revision of glaucoma drainage device filtering blebs [published erratum]. Ophthalmology 1997;104:1532.

29 Freedman J. Scleral patch grafts with Molteno setons. Ophthalmic Surg 1987; 18:532-4.

30 Brandt JD. Patch grafts of dehydrated cadaveric dura mater for tube-shunt glaucoma surgery. Arch Ophthalmol 1993;111:1436-9.
31 Tanji TM, Lundy DC, Minckler DS, et al. Fascia lata patch graft in glaucoma tube surgery. Ophthalmology 1996;103:1309-12.

32 Raviv T, Greenfield DS, Liebman JM, et al. Pericardial patch grafts in glaucoma implant surgery. J Glaucoma 1998;7:27-32.

33 Aslanides IM, Spaeth GL, Schmidt CM, et al. Autologous patch graft in tube shunt surgery. J Glaucoma 1999:8:306-9.

34 Osata MS. Normal ocular flora. In: Pepose JS, Holland GN, Wilhelmus KR, eds. Ocular infection and immunity. St Louis: Mosby, 1996:191-9.

35 Kaplan SL, Feigin RD. Haemophilus influenzae. In: Behrman RE, Kliegman RM, eds. Nelson textbook of pediatrics, 14th ed. Philadelphia: Saunders, 1992:711-13.

36 Ellis BD, Varley GA, Kalenak JW, et al. Bacterial endophthalmitis following cataract surgery in an eye with a preexisting Molteno implant. Ophthalmic Surg 1993;24:117-18.

\section{Video reports}

To view the video reports in full visit our website www.bjophthalmol.com and click on the link to the video reports.

- The Nuclear Slide: A novel approach for unleashing the potential of the hydrodissection wave. A Naseri

- Giant pleomorphic adenoma of the lacrimal gland: pre- and post-operative function. A Jain, VI Nehru, U N Saikia, C E E Reddy

- Limbal-sparing lamellar keratoplasty. S L Watson, S Rauz, J Dart

- Bilateral Abducens Neuromyotonia. L H Ospina, N Aui-aree, D P Anderson

- Light to dark physiological variation in irido-trabecular angle width. GM Gazzard, P J Foster, D S Friedman, P T Khaw, S K L Seah

Video Suite: Triamcinolone-assisted vitrectomy

- Triamcinolone-assisted removal of the posterior hyaloid to repair retinal detachment due to macular hole in high myopia. A Ueno, H Enaida, Y Hata, T Nakamura, T Hisatomi, K Fujisawa, T Kubota, T Sakamoto, T Ishibashi

- Triamcinolone acetonide-assisted Epiretinal Membrane Peeling. S D M Chen, CK Patel

- A suture technique to manage a case of severe early flap displacement after laser in situ keratomileusis. L Spadea, P Pantaleoni, G Bianco

- Reconstruction of the Ocular Surface in LOGIC Syndrome. E Moore, V Kumar, $J$ R Ainsworth, S Shah

- Laser Photocoagulation for Posterior Segment Intraocular Parasites. T Prabriputaloong, S Asawaphureekorn

- Feeder Vessel Treatment with High Speed ICG Angiography. D Stanescu-Segall, G Coscas, F Coscas, G Soubrane

- Endoscopy to aid anterior segment surgery. J E Moore, A Sharm

- Penetrating ocular injury due to a fish hook: Surgical removal. SD M Chen, D Chiv, C K Patel

- Retinal Ganglion Cell Axon Response to Guidance Molecules. S F Oster and D W Sretavan

- Marin-Amat Syndrome. A Jogiya, C Sandy

- Excision of subcutaneous Dirofilariasis of the eyelid. D Mallick, T P Ittyerah

- Thixotropy: a novel explanation for the cause of lagophthalmos after peripheral facial nerve palsy. M Aramideh, J H T M Koelman, P P Devriese, F VanderWerf, J D Speelman

- Surgical revision of leaking filtering blebs with an autologous conjunctival graft. K Taherian, A Azuara-Blanco

- Dipetalonema Reconditum in the human eye. THuynh, J Thean, R Maini 